\title{
A "TERCEIRA MARGEM" DOS DIREITOS HUMANOS: PARA ALÉM DO PODER PUNITIVO VIA MANDADO DE BUSCA E APREENSÃO COLETIVO
}

\section{A "THIRD BANK" OF HUMAN RIGTHS: IN ADDITION TO THE PUNITIVE POWER BY SEARCH AND SEIZURE WARRANT COLLECTIVE}

\begin{abstract}
LARISSA ROSA
Mestranda em Direito pela Faculdade de Ciências Humanas e Sociais da UNESP, Franca, São Paulo, Brasil. Pósgraduada em Direito Constitucional pela Universidade Anhanguera Uniderp.
\end{abstract}

Larissa_51@hotmail.com

\begin{abstract}
Marisa Helena D’Arbo Alves de Freitas
Doutora em Direito pela UNESP. Professora da Graduação e do Programa de Mestrado em Direito da Faculdade de Ciências Humanas e Sociais da UNESP, Franca, São Paulo, Brasil. Professora da Universidade Paulista (UNIP), Ribeirão Preto, São Paulo, Brasil. Membro do Núcleo de Estudos da Tutela Penal e Educação em Direitos Humanos - NETPDH. madarbo@uol.com.br

Renan Possela MANDARINo Mestrando em Direito pela Faculdade de Ciências Humanas e Sociais da UNESP, Franca, São Paulo, Brasil. Pósgraduado em Direito Penal e Processual Penal pela Fundação Armando Alvares Penteado (FAAP). Bolsista CAPES/PROPG. renan.mandarino@agtm.adv.br
\end{abstract}

\section{RESUMO}

0 trabalho analisa as perversidades do poder punitivo, através da ordem de busca e apreensão coletiva, e as suas consequências na efetividade dos direitos humanos. Como método de abordagem, estabelece-se um "diálogo" com o conto "A terceira margem do rio", de João Guimarães Rosa, utilizando a literatura brasileira como instrumento de crítica ao direito. Inicialmente, discorre-se sobre as linhas gerais da inversão ideológica dos direitos humanos na perspectiva da tutela penal, com a finalidade de demonstrar as armadilhas existentes na idealização do discurso garantista. Em seguida, perpassa-se ao exame do mandado de busca e apreensão coletivo e seu confronto com os direitos fundamentais. Mais a frente, o trabalho apresenta a literatura rosiana para a compreensão crítica do tema em debate, traçando uma interpretação analógica entre "A terceira margem do rio" e os direitos humanos. A conclusão é que o conteúdo abstrato e normativo dos direitos humanos não limita o controle punitivo.

Palavras-chave: Busca e apreensão coletiva; Direitos humanos; Poder punitivo; Tutela penal.

\begin{abstract}
The work analyses the perversity of punitive power, through the order of search and seizure collective and its consequences for the effectiveness of human rights. As approach method, it establishes a "dialog" with the story "The third bank of river", from João Guimarães Rosa, using the brazilian literature as an instrument for a critic of the law. Initially, discouser on the general lines of ideological reversal of human rights from the perspective of criminal protection, with the purpose os demonstrating existing traps in the idealization of speech guarantees. Then, it cuts across the examination of the search and seizure warrant collective and confrontation with fundamental rights. Foward, the work presents rosiana literature to critical understanding of subject under discussion, outlining a analogical interpretation between the "Third bank of river" and human rights. The conclusion is that the abstract and normative content of human rights does not limit the punitive control.
\end{abstract}

Keywords: Search and seizure collective; Human rights; Punitive power; Criminal protection. 


\section{SUMÁRIO}

INTRODUÇAO; 1 INVERSÃO IDEOLÓGICA DOS DIREITOS HUMANOS NA PERSPECTIVA DA TUTELA PENAL; 2 O MANDADO DE BUSCA E APREENSÃO COLETIVO EM CONFRONTO COM OS DIREITOS FUNDAMENTAIS: A REVERSIBILIDADE DAS GARANTIAS PROCESSUAIS PENAIS; 3 A TERCEIRA MARGEM DO RIO: UM DIÁLOGO CRÍTICO COM OS DIREITOS HUMANOS; 4 A “TERCEIRA MARGEM" DOS DIREITOS HUMANOS: PARA ALÉM DO PODER PUNITIVO VIA MANDADO DE BUSCA E APREENSÃO COLETIVO; CONCLUSÃO; REFERÊNCIAS.

\section{INTRODUÇÃO}

Recentemente, tornou-se praxe dos juízes, após pedido da autoridade policial e com a anuência de membro do Ministério Público, expedir ordem de busca e apreensão coletiva e genérica, com a finalidade de autorizar o ingresso arbitrário de agentes policiais em quaisquer domicílios nas favelas e bairros periféricos para persecução de práticas criminosas.

Essa é uma realidade recorrente em diversas regiões do Brasil, como por exemplo, no Rio de Janeiro, com a ocupação da favela da maré ${ }^{1}$, e em Fortaleza, na comunidade Lagoa Seca ${ }^{2}$. A inviolabilidade de domicílio é um direito consagrado nas constituições dos Estados Democráticos de Direito e, no Brasil, essa garantia é assegurada desde a Constituição de 1824. Atualmente, ela é um direito fundamental insculpido no artigo $5^{\circ}$, inciso $\mathrm{XI}$ do texto constitucional e, como regra, não se permite a entrada em casa alheia sem o consentimento do morador, reservando-the a sua intimidade e a sua vida privada.

Ressalvadas as hipóteses excepcionais de flagrante delito ou desastre, o ingresso no domicílio de um cidadão somente pode ocorrer em decorrência de determinação judicial. Essa é uma cláusula de reserva jurisdicional, com atribuição exclusiva do Poder Judiciário para, fundado nas normas limitadoras do código de processo penal, determinar a busca nos domicílios.

\footnotetext{
${ }^{1}$ CORRÊA, Douglas. Mandado de busca coletivo autoriza revista a casas do Complexo da Maré. UOL notícias cotidiano, Rio de janeiro, 30 mar. 2014. Disponível em: <http://noticias.uol.com.br/cotidiano/ultimas-noticias/2014/03/30/mandado-de-busca-coletivo-autorizarevista-a-casas-do-complexo-da-mare.htm>. Acesso em: 03 abr. 2015.

${ }^{2}$ G1 GLOBO. SSPDS cumpre mandado de busca e apreensão coletivo em comunidade. Disponível em: <http://g1.globo.com/ceara/noticia/2014/08/sspds-cumpre-mandado-de-busca-e-apreensao-coletivo-emcomunidade.html>. Acesso em: 19 jan. 2015.
} 


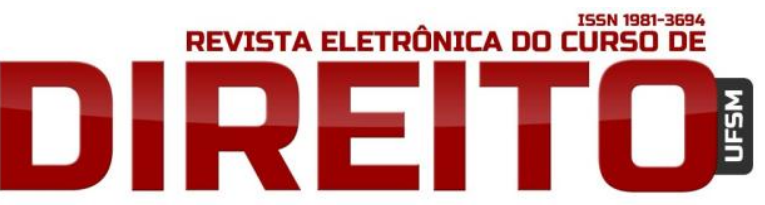

A "TERCEIRA MARGEM" DOS DIREITOS HUMANOS: PARA ALÉM DO PODER PUNITIVO VIA MANDADO DE BUSCA E APREENSÃO COLETIVO

larissa Rosa, Marisa Helena D’arbo Alves de Freitas, RENAN POSELLA MANDARINO

Entretanto, por detrás do controle punitivo manejado pelos mandados de busca e apreensão coletivos, persiste uma armadilha ideológica na utilização da tutela penal dos direitos humanos.

O objetivo do trabalho é analisar as perversidades do poder punitivo, através da ordem de busca e apreensão coletiva, e as suas consequências na efetividade dos direitos humanos. Para abordagem da temática, insta estabelecer um "diálogo" com o conto literário "a terceira margem do rio", de João Guimarães Rosa, com o escopo de empregar a literatura brasileira como instrumento de crítica ao direito.

Inicialmente, discorre-se sobre as linhas gerais da inversão ideológica dos direitos humanos na perspectiva da tutela penal, com a finalidade de demonstrar as armadilhas existentes na idealização do discurso garantista processual penal. Em seguida, passa-se ao exame da relação existente entre a inversão ideológica dos direitos humanos e o mandado de busca e apreensão coletivo. Por fim, o trabalho apresenta a literatura de Guimarães Rosa como instrumento de compreensão crítica da temática em debate, traçando os pontos de intersecção entre o conto "terceira margem do rio" e os direitos humanos.

\section{INVERSÃO IDEOLÓGICA DOS DIREITOS HUMANOS NA PERSPECTIVA DA TUTELA PENAL}

O mote popular que rege a sociedade moderna é o ceticismo na efetividade da tutela penal, sob a justificativa de que o fracasso da justiça criminal residiria essencialmente nas parcas penas aplicadas pelo Estado e no ineficiente controle punitivo deste. A sensação do risco, caracterizada pela impotência estatal para apresentar respostas adequadas às expectativas dos cidadãos, enseja uma desenfreada busca por referenciais de segurança.

É instaurado nas pessoas um quadro de “insegurança ontológica”, ou seja, uma ansiedade de ser engolfado, esmagado ou sufocado por elementos externos, os quais geram excessivas preocupações e medo dos riscos possíveis para a sua existência ${ }^{3}$.

As crenças se tornam voláteis e não há o necessário poder de consolidação. Diante da insegurança ontológica, há tentativas de criar uma base segura. 0 homem tende a buscar a sua

${ }^{3}$ GIDDENS, Anthony. Modernidade e identidade. Tradução de Plínio Dentzien. Rio de Janeiro: Jorge Zahar, 2002, p. 55. 
A “TERCEIRA MARGEM" DOS DIREITOS HUMANOS: PARA ALÉM DO PODER PUNITIVO VIA MANDADO DE BUSCA E APREENSÃO COLETIVO

segurança nos sentimentos que the afloram, o que, na esfera do controle social, vem acompanhado da formação de uma cultura punitiva. Paulatinamente, sedimenta-se a convicção da necessidade de punições severas como solução do problema da criminalidade, crença esta que é potencializada pelos meios de comunicação de massa (mass media) para se fabricar o consenso punitivo.

No contexto da sociedade punitiva contemporânea, a ideia hegemônica de insegurança provoca a perpetuação da dominação autoritária pelos mecanismos institucionais. Os direitos fundamentais são encarados como entraves à exploração do poder punitivo e, como consequência, as garantias mínimas limitadas constitucionalmente são desrespeitadas pelas abusivas e violentas medidas penais ${ }^{4}$.

$\mathrm{Na}$ tentativa de legitimar a opinião pública, há a recuperação dos fundamentos da ideologia da defesa social, o que faz com que o sistema penal alimente a perversa lógica seletiva, na qual parte dos humanos é tratada como inimigo e a outra parcela como cidadão, este sim sujeito apto a receber a tutela dos direitos fundamentais. David Garland explica que o populismo penal se tornou o tema dominante da política criminal:

Proteger o público é preocupação perene da política criminal e isso se reflete expressamente nos sistemas correcionais. Afinal de contas, foram os reformistas do bem-estar penal que inventaram a detenção preventiva e as sentenças condenatórias de tempo indeterminado; o sistema que operou durante a maioria do século XX reservou poderes especiais para encarcerar criminosos 'incorrigíveis' e perigosos por períodos indeterminados. No entanto, numa época em que os índices de criminalidade eram baixos e o medo do crime ainda não era mote político, a proteção do público raramente servia de motivação para elaboração de políticas públicas. Hoje em dia, há uma nova e urgente ênfase na necessidade de segurança, na contenção do perigo, na identificação e gerenciamento de riscos de todos os tipos ${ }^{5}$.

Nessa toada populista, os direitos humanos se apresentam como instrumento de proteção da população "sofrida", "desamparadas" (assim se intitulam as vítimas dos delitos e os membros angustiados do público). 0 controle punitivo torna-se legítimo aparato de neutralização e retribuição para satisfazer as exigências políticas populares por segurança e punições severas.

\footnotetext{
${ }^{4}$ BIZZOTTO, Alexandre. A inversão ideológica do discurso garantista: a subversão da finalidade das normas constitucionais de conteúdo limitativo para ampliação do sistema penal. Rio de Janeiro: Lumen Juris, 2009, p. 105.

${ }^{5}$ GARLAND, David. A cultura do controle: crime e ordem social na sociedade contemporânea. Pensamento criminológico, vol. 16. Rio de Janeiro: Revan, 2008, p. 56-57.
} 
A "TERCEIRA MARGEM" DOS DIREITOS HUMANOS: PARA ALÉM DO PODER PUNITIVO VIA MANDADO DE BUSCA E APREENSÃO COLETIVO

Latente o conflito entre a necessidade de aplicabilidade das previsões normativas constitucionais, base positivada dos direitos humanos, e os anseios produzidos pela sociedade repressora. É justamente esse embate retórico que fundamenta a inversão ideológica dos direitos humanos, ou seja, existe uma espécie de banalização do discurso de "proteção" aos direitos humanos, que tornam o seu termo objeto de disputas para que possa ser manipulado consoante os interesses em jogo ${ }^{6}$.

A fundamentação utilizada para respaldar os interesses do Estado, ao se alegar que este necessita tutelar os direitos pertinentes às diversas tutelas públicas (segurança, ordem, saúde, economia), é consequência de idealizações que ilusoriamente pressupõem o Estado como o detentor do reconhecimento e da concessão dos direitos humanos. Tal linha de raciocínio enseja permissão de posturas autoritárias, posto deixar os direitos humanos da pessoa concreta subordinados à vontade estatal.

Conforme pondera Salo de Carvalho, a inversão ideológica dos direitos humanos pode ser conceituada como a "criação de justificativas e mecanismos aparentemente voltados à satisfação dos direitos humanos, mas que, em sua ação concreta, deflagram violações dos próprios direitos humanos"7.

A percepção do movimento de inversão ideológica dos direitos humanos não se limita à ciência jurídica. No plano cultural, outras vozes se levantam para o uso empedernido dos direitos fundamentais. Gabriel, O Pensador, na música “O cachimbo da paz", relata a história de um índio cacique que ao chegar à cidade se depara com a criminalidade e a violência. Ao ser flagrado com porte de droga, o índio é levado à prisão, momento em que, sem compreender os motivos de sua segregação, promove reflexões sobre a "nova" tribo:

[...] Na penitenciária o "índio fora da lei"/Conheceu os criminosos de verdade/ Entrando, saindo e voltando cada vez mais perigosos para a sociedade/ "Aí cumpádi, tá rolando um sorteio na prisão/ Pra reduzir a superlotação"/ Todo mês alguns presos têm que ser executados/ E o índio, dessa vez, foi um dos sorteados/ E tentou acalmar as outros presos/ "Peraí, vamos fumar um cachimbinho da paz"/ Eles começaram a rir e espancaram o velho índio até não poder mais/ E antes de morrer ele pensou: "Essa tribo é atrasada demais/ Eles querem acabar com a violência, mas a paz é contra a lei e a lei é contra a paz"/ E o cachimbo do índio continua proibido/Mas se você quer comprar é mais fácil que pão/ Hoje em dia ele é vendido pelos mesmo bandidos/ Que mataram o velho índio na prisão [...].

\footnotetext{
${ }^{6}$ CARVALHO, Salo de. Antimanual de criminologia. 4. ed. Rio de Janeiro: Lumen Juris, 2011, p. 111.

${ }^{7}$ CARVALHO, Salo de. Antimanual de criminologia, p. 112.
} 
Depreende-se que o cacique, imbuído pela cultura e realidade de seu povo, vislumbrou que a sociedade não-indígena não conseguia superar a violência em razão das incongruências normativas. Esse raciocínio esboçado na canção ampara os argumentos da teoria crítica dos direitos humanos: a) a afirmação da ausência de integração entre a vida humana real e o humano, com a abstração teórica predominando sobre a realidade; b) a necessidade de se conferir um ponto de vista sociológico e valorativo a respeito dos direitos humanos; c) o despedaçamento dos direitos humanos e a falsa contraposição entre as dimensões dos direitos; d) a falta de efetivação dos direitos humanos com a necessidade de se criar uma ideia de resistência às agressões aos direitos humanos; e) a excessiva confiança no nível normativopositivo dos ordenamentos jurídicos ${ }^{8}$.

A abstração dos direitos humanos debilita a concretude social. É muito comum, ao se enfrentar as teorias de direitos humanos, a categorização das pessoas em modelos abstratos. Aquelas que não se encaixam na classificação são subliminarmente rebaixadas da categoria humana. A perspectiva abstrata sobre as pessoas permite a abertura para o florescimento de entendimentos que defendem a hegemonia de grupos sobre outros grupos, numa estreita relação de dominação (sujeito-objeto). O sujeito concreto torna-se um pária humano caso não atenda aos padrões de direitos humanos impostos por aqueles que prestam bons serviços ao mercado global.

Distanciam-se e abstraem-se direitos humanos das bases fundantes necessárias para que sejam e estejam profundamente concretizados nas vivências cotidianos nos indivíduos e grupos sociais. $O$ intuito de descontextualizar direitos humanos, ao preencher de abstrações seus conteúdos e desmerecer os processos e lutas para seu surgimento e sua expansão, caminha no sentido de reproduzir ideais, valores e concepções que contribuam para a manutenção das estruturas de dominação e opressão?.

Gallardo Martínez aponta para o problema do caráter metafísico da noção de humanidade $^{10}$. Pondera que há um imaginário ideológico, no qual os conceitos e valores de

\footnotetext{
${ }^{8}$ HERRERA FLORES, Joaquín. La Reinvención de los Derechos Humanos. Colección Ensayando. Sevilla: Atrapasueños, 2007, p. 30.

${ }^{9}$ FALEIROS JÚNIOR, Roberto Galvão. Tutela penal e teoria crítica de direitos humanos: uma intersecção crítico-dialética marginal. 2012. 204 f. Dissertação (Mestrado em Direito) - Universidade Estadual Paulista. Faculdade de Ciências Humanas e Sociais, Franca, 2012, p. 141.

${ }^{10}$ GALLARDO MARTíNEZ, Helio. Teoría crítica: matriz y posibilidad de derechos humanos. Murcia: Editado por David Sánchez Rubio, 2008, p. 180.
} 
justiça ao mesmo tempo em que flutuam por sobre as tramas sociais e as "deshistoricizam" como função da reprodução das dominações vigentes, também incidem normativamente. Para o cidadão comum e setores sociais populares, a "justiça” pode representar algo de que carecem, mas que algum dia chegará (em outra vida ou através de uma decisão do poder judiciário). Tal argumento metafísico tanto pode causar a inclusão como a exclusão social, o que foge aos preceitos essenciais da dignidade humana.

Outro elemento crítico é a necessidade de redimensionar as abstrações dos direitos humanos, com a finalidade de examinar o direito a partir de um ponto de vista sociológico e valorativo que atenda a sua complexa realidade e estrutura. Imperiosa a assunção de um pensamento relacional, interdisciplinar e pluralista do sistema jurídico, de forma que não se resuma ao plano retórico ${ }^{11}$.

Os direitos humanos precisam se adequar às condições históricas de cada povo, sem modelação de padrões. A compreensão de direito no Ocidente não é a mesma no Oriente. É preciso avaliar as necessidades humanas que surgem em cada contexto sociocultural. Desmembrar a realidade social e seus valores dos direitos humanos pode provocar novos conflitos em vez de proteger os direitos das pessoas.

O despedaçamento dos direitos humanos é outro fator inerente ao seu enfraquecimento. A visão geracional dos direitos é simplista, estreita e reduzida, pois provoca verta indolência, docilidade e passividade, além de consolidar a cisão entre teoria e prática. A falsa ideia de hierarquização das dimensões serve apenas para fomentar a rivalidade entre os titulares e interessados na tutela preferencial dos direitos individuais, sociais ou transindividuais, conduzindo à perda do sentido reverencial dos direitos humanos.

David Sánchez Rúbio enfatiza que os direitos humanos em suas dimensões são complementares entre si e não fragmentários. A visão geracional passa a impressão de que os direitos fundamentais são como uma espécie de traje ou vestimenta, com paletó e gravata, que todos devem colocar, inclusive aqueles que não necessitam usá-lo ou não se encaixem neste modelo ${ }^{12}$.

\footnotetext{
11 SÁNCHEZ RÚBIO, David. Encantos e desencantos dos direitos humanos: emancipações, libertações e dominações. Porto Alegre: Livraria do Advogado, 2014, p. 30-46.

12 SÁNCHEZ RÚBIO, David. Encantos e desencantos dos direitos humanos: emancipações, libertações e dominações, p. 87-92.
} 
A “TERCEIRA MARGEM" DOS DIREITOS HUMANOS: PARA ALÉM DO PODER PUNITIVO VIA MANDADO DE BUSCA E APREENSÃO COLETIVO

Com a hierarquização, o apelo à tutela aos direitos sociais e transindividuais, que têm maior apelo público, implica o esvaziamento da força dos direitos individuais. 0 senso comum jurídico demoniza os direitos individuais.

Outro problema apontado pela teoria crítica diz respeito à inefetividade dos direitos. 0 catálogo de normatização existente sobre os direitos humanos não é suficiente para que tais proteções ganhem corpo próprio. É imprescindível promover e incentivar a ideia de resistência a favor dos direitos humanos. A preocupação com estes direitos apenas surgem quando há a afetação concreta e pessoal, ignorando a sua necessidade de proteção quando a lesão ocorre com os outros. Não se percebe alteridade nas relações humanas e não há apoios institucionais para promover o engajamento das pessoas para a emancipação das pessoas. Insta salientar que a efetividade dos direitos humanos depende da conjuntura real das relações sociais e não da mera positividade pelo Estado ${ }^{13}$.

Existe uma perceptível relação de dominação entre sujeitos humanos provocada pela excessiva confiança na legislação. Esse ponto constitui a principal crítica da inversão ideológica dos direitos humanos. Os comandos normativos não são salvadores de todos os problemas da sociedade. É relevante ter a garantia da previsão no ordenamento jurídico, contudo, a simples enunciação não modifica realidades oriundas no contexto das questões humanas.

Roberto Galvão Faleiros Júnior apresenta críticas ao imaginário ideológico positivista, reduzido a uma dimensão formal e ritualística:

O imaginário ideológico, que hegemoniza e homogeneíza qualquer abordagem sobre direitos humanos, é a própria cultura jurídica contemporânea que se demonstra analfabeta e anestésica nestes quesitos. Simplificam e despolitizam os fundamentos sobre esses direitos e privilegiam sua dimensão normativa, supervalorizando 0 aspecto pós-violatório e desconsiderando qualquer emergência ou surgimento fora das estruturas institucionais. Reduzem, assim, direitos humanos às concepções filosóficas, previsões normativas e vínculos institucionais e à eficácia jurídica oriunda do Estado ${ }^{14}$.

\footnotetext{
${ }^{13}$ BIZZOTTO, Alexandre. A inversão ideológica do discurso garantista: a subversão da finalidade das normas constitucionais de conteúdo limitativo para ampliação do sistema penal, p. 121.

${ }^{14}$ FALEIROS JÚNIOR, Roberto Galvão. Tutela penal e teoria crítica de direitos humanos: uma intersecção crítico-dialética marginal, p. 154.
} 
A “TERCEIRA MARGEM" DOS DIREITOS HUMANOS: PARA ALÉM DO PODER PUNITIVO VIA MANDADO DE BUSCA E APREENSÃO COLETIVO

No âmbito da tutela penal, esses argumentos apontados pela teoria crítica se imbricam, gerando a "reversibilidade" ${ }^{15}$ dos direitos fundamentais. Há uma manipulação simbólica do sistema de proteção penal para anestesiar a sociedade e encobrir a cruel realidade dos direitos humanos. As garantias processuais penais são utilizadas como instrumento de manejo discursivo para atender interesses da classe dominante (discurso da paz, direitos humanos das vítimas, defesa social, etc.) e justificar as ações punitivas. No plano concreto, os mandados de busca e apreensão coletivo são o reflexo dessa ampliação violenta do controle penal e da perversão das instâncias formais.

\section{MANDADO DE BUSCA E APREENSÃO COLETIVO EM CONFRONTO COM OS DIREITOS FUNDAMENTAIS: A REVERSIBILIDADE DAS GARANTIAS PROCESSUAIS PENAIS.}

Dogmática penal, poder punitivo e legalidade: gravitam sobre essas três palavras o discurso oficial legitimador do controle funcional do sistema de justiça penal. Zaffaroni afirma que a dogmática penal (“discurso dos juristas”) não se confunde com a normatividade penal ("ato do poder político") e com poder punitivo ${ }^{16}$. O direito penal é ramo do saber jurídico que, mediante interpretação das leis penais, propõe ao juiz um sistema orientador de decisões que contém e reduz o poder punitivo para impulsionar o progresso do estado constitucional de direito.

Numa análise relacional apta a contrastar a programação normativa com a operacionalidade do sistema penal, enquanto conjunto de ações e decisões, vislumbra-se a incongruência entre a operacionalidade (ser) e a programação (dever ser), entre a realidade social e o postulado jurídico.

15 O autor apresenta como característica principal do fenômeno da "inversão ideológica" a "reversibilidade". Afirma ser esta a condição do direito ser interpretado e aplicado em um ou outro sentido, inclusive contraditórios entre si. 'É uma distorção do reflexo entre pensamento e realidade (SÁNCHEZ RÚBIO, David. Reversibilidade do direito: os direitos humanos na tensão entre o mercado, os seres humanos e a natureza. Revista de Estudos Criminais, ano VI, $\mathrm{n}^{\circ} 22$. Porto Alegre: Notadez/PPGCRIm PUCRS/ITEC, 2006, p. 23).

${ }_{16}$ ZAFFARONI, Eugenio Raúl; BATISTA, Nilo; ALAGAIA, Alejandro; SLOKAR, Alejandro. Direito penal brasileiro: primeiro volume - parte geral. Rio de Janeiro: Revan, 2003, p. 38-40. 
Insta assinalar que o Estado condiciona a natureza do sistema criminal a um controle centralizado, racionalizado e burocratizado. Ao mesmo tempo em que institucionaliza o monopólio da violência física e do poder político, através do controle e domínio, a matriz estatal necessita formalmente de discursividades ("saberes" e “ideologias") tão aptas para o exercício efetivo deste controle quanto para a sua justificação e legitimação. Para além de um monopólio detido pelo Estado, o sistema delitivo é um exercício de poder e de funções ${ }^{17}$.

A legitimidade do sistema penal é utópica, no sentido de que a racionalidade do discurso jurídico-penal é ilusória, pois o poder punitivo não opera somente fundado na legalidade formal. A mesma lei que prevê a norma criminalizadora, com a obediência aos rigorosos ritos processuais penais, renuncia a legalidade ao excluir do seu âmbito o exercício de poder das agências policiais e ao garantir autonomia interpretativa nas decisões do poder judiciário. As agências legislativas apenas fornecem uma reduzida parte da realidade social, pois o verdadeiro e real poder do sistema penal é o poder configurador positivo, exercido à margem da legalidade e com altíssimo grau de discricionariedade e seletividade.

A repressão (aspecto negativo) representa somente um limite ao exercício do poder. 0 poder mais perverso é o positivo, configurador, aquele em que

Mediante a expressa renúncia à legalidade penal, os órgãos do sistema penal são encarregados de um controle social militarizado e verticalizado, de uso cotidiano, exercido sobre a maioria da população, que se estende além do alcance meramente repressivo, por ser substancialmente configurador da vida social $^{18}$.

Uma das formas de concretização do poder disciplinar configurador é o mandado de busca e apreensão coletivo, que consiste na medida outorgada pelo poder judiciário às agências policiais para que, respaldadas numa espúria legalidade, controlem e previnam a ocorrência de delitos. Contudo, é um poder insidiosamente verticalizante e seletivo.

A ordem de busca e apreensão possui duas naturezas. É uma medida instrumental, meio de obtenção de prova que visa encontrar pessoas ou coisas (busca) e, ao mesmo tempo, é uma

\footnotetext{
${ }^{17}$ ANDRADE, Vera Regina Pereira de. A ilusão de segurança jurídica: do controle da violência à violência do controle penal. Porto Alegre: Livraria do Advogado, 2003, p. 176.

${ }_{18}$ ZAFFARONI, Eugenio Raúl. Em busca de las penas perdidas: Deslegitimacion y dogmática juridicopenal. 2. ed. Buenos Aires: EDIAR, 1998, p. 27-28.
} 
medida cautelar probatória (apreensão), pois se destina à garantia da prova e, ainda, dependendo do caso, para a própria restituição do bem a seu legítimo dono, assumindo também uma feição de medida assecuratória. Tal medida está em constante tensão com os direitos fundamentais como inviolabilidade do domicílio, dignidade da pessoa humana, intimidade e a vida privada e incolumidade física e moral do indivíduo ${ }^{19}$.

A realização do mandado de busca e apreensão deve sempre estar conectado com o direito fundamental da intimidade e vida privada (art. $5^{\circ}$, inciso X, Constituição Federal), pois a tutela do domicílio guarda conexão instrumental com os demais direitos fundamentais e com o valor dignidade da pessoa humana. Essa imbricação entre os direitos fundamentais gera reflexos na eficácia dos limites legais estabelecidos para cumprimento da ordem de busca, na medida em que não se tutela apenas o espaço físico ou propriedade, mas também o cuidado na divulgação dos materiais apreendidos para não gerar constrangimentos desnecessários ao sujeito ${ }^{20}$.

Como consequência dessa constante tensão com os direitos fundamentais, a forma é garantia inarredável para inviolabilidade da busca e apreensão domiciliar. Dentre as legalidades previstas, imprescindível a indicação da casa ou local onde a busca será realizada, pois não se busca para investigar, senão que se investigue primeiro e, apenas quando necessário, postula-se a busca e apreensão. A inobservância, ausência ou deficiência no atendimento dos requisitos legais torna ineficaz o ato procedimental e, portanto, inadmissível mandado de busca e apreensão genérico, abrangendo local e pessoa indeterminados ${ }^{21}$.

É imperioso, para a validade do ato, que o mandado de busca e apreensão tenha um escopo previamente definido. Logo, mandado incerto, vago ou genérico goza de ilegalidade. A determinação do varejamento, ou da revista, há de apontar, de forma clara, o local, o motivo da procura e a finalidade, além de qual a autoridade judiciária que a expediu. A indicação minuciosa do motivo e fins da diligência é de suma importância, como bem tutela o artigo 240 e 243 do código de processo penal.

\footnotetext{
19 LOPES JUNIOR, Aury. Direito Processual Penal. 11. ed. São Paulo: Saraiva, 2014, p. 721-722.

${ }^{20}$ SARLET, Ingo Wolfgang; NETO, Jayme Weingartner. A inviolabilidade do domicílio e seus limites: o caso do flagrante delito. Revista de Direitos Fundamentais e Democracia, Curitiba, v. 14, n. 14, p. 544-562, jul./dez. 2013, p. 559.

21 PITOMBO, Cleunice Valentim Bastos. Licitude da prova obtida por meio da busca e da apreensão. In: VILARD, Celso Sanchez; PEREIRA, Flávia Rahal Bresser; NETO, Theodomiro Dias Neto. Direito penal econômico: crimes econômicos e processo penal. São Paulo: Saraiva, 2008, p. 80.
} 
Entretanto, a previsão normativa incide seletivamente. Há uma inversão ideológica desse discurso garantista, com a aplicação da medida de busca e apreensão coletiva limitada aos setores vulneráveis da sociedade, numa visível tentativa de eliminação do "outro" e dominação do sujeito humano, conforme pondera Aury Lopes Junior:

Situação absurda, que infelizmente tem se tornado comum, são os mandados de busca e apreensão genéricos, muitas vezes autorizando a diligência em quarteirões inteiros (obviamente na periferia...), conjuntos residenciais ou mesmo nas "favelas" de tal ou qual vila. Claro que os juízes somente expedem tais monstruosidades jurídicas quando se trata de barbarizar os clientes preferenciais do excludente sistema implantado, aqueles para quem a proteção constitucional da casa (e demais direitos fundamentais) é ineficaz, até porque favela e barraco não são casas... e quem lá (sobre)vive não merece nenhuma proteção, pois são os "outros" ou, ainda, a multidão de invisíveis ${ }^{22}$.

Por se oriundo de uma produção humana, os direitos são políticos e ideológicos. As práticas, os discursos e as teorias são utilizados como ferramentas de manutenção de uma cultura jurídica dominante que oprime a casta mais vulnerável e liberta grupos detentores de poderes políticos e econômicos. Isso é facilmente percebido nas decisões que autorizam ou negam as ordens de busca e apreensão genérica.

Ao pesquisar julgados relativos à matéria de busca e apreensão genérica, constata-se que um mesmo tribunal tem posições diferentes, a depender da natureza e das condições fáticas do delito. Nos casos de tráfico ilícito de entorpecentes, cuja investigação via ordem de busca ocorre nas favelas e comunidades, é válido o mandado por se tratar de crime permanente que, inclusive, dispensaria a ordem escrita ${ }^{23}$. Na outra extremidade, nos crimes de colarinho branco, corrupção e lavagem de dinheiro, cuja apuração via ordem de busca ocorre nas empresas com grande poderio econômico, o mandado de busca genérico não é válido, pois afronta princípios constitucionais e macula a honra e dignidade do cidadão investigado. ${ }^{24}$

Cingindo ainda mais a análise desse descompasso jurisprudencial é possível constatar que a inversão ideológica pode advir, inclusive, de uma mesma turma julgadora. É o que se

\footnotetext{
22 LOPES JUNIOR, Aury. Direito Processual Penal, p. 731.

23 Tribunal de Justiça do Estado de São Paulo. Apelação no 9000011-34.2010.8.26.0127. 14a Câmara de Direito Criminal. Desembargador relator Miguel Marques e Silva. Data do julgamento 07 de março de 2013. No mesmo sentido: Apelação $\mathrm{n}^{\circ}$ 0068558-59.2009.8.26.0050. $15^{\mathrm{a}}$ Câmara de Direito Criminal. Desembargador relator Nelson Fonseca Junior. Data do julgamento 13 de março de 2014.

${ }^{24}$ Tribunal de Justiça do Estado de São Paulo. Apelação n 990.08.003501-0 e 993.08.039126-2. $5^{\text {a }}$ Câmara de Direito Criminal. Desembargador relator Pinheiro Franco. Data do julgamento 09 de outubro de 2008.
} 
A "TERCEIRA MARGEM" DOS DIREITOS HUMANOS: PARA ALÉM DO PODER PUNITIVO VIA MANDADO DE BUSCA E APREENSÃO COLETIVO

Larissa Rosa, marisa Helena d’ARbo Alves de Freitas, RENAN POSELLA MANDARINO

depreende da leitura das decisões proferidas pelo Superior Tribunal de Justiça. Altera-se o órgão judicante, mas permanece o discurso conservador: na hipótese de narcotraficância admite-se a invasão domiciliar, independente de mandado judicial, "para reprimir e fazer cessar a ação delituosa"25. Todavia, na hipótese de crime contra a ordem tributária, a "apreensão de documentos contábeis na empresa, sem autorização judicial, é constrangedora e afronta a garantia de inviolabilidade de domicílio"26.

Apesar da persuasão argumentativa utilizada nas decisões, percebe-se que os direitos positivados possuem interpretações distintas para cada grupo socioeconômico. 0 caráter seletivo e neutralizador do sistema penal é acentuado nas comunidades subalternizadas, setores sociais vulneráveis ao poder punitivo configurador. Essa ideologia constantemente reproduzida nas decisões judiciais é fruto da ausência de resistência das minorias, que convivem cotidianamente com as arbitrariedades policiais transvestidas de "aparente" legalidade.

Dados de 2013 divulgados pelo Sistema Integrado de Informações penitenciárias (InfoPen) ${ }^{27}$ apontaram que do total da população carcerária do Brasil, 574.027 presos, 270.247 haviam cometido crimes contra patrimônio e 146.276 praticaram crimes de tráfico de entorpecentes. A conclusão a que se chega é que $72,56 \%$ dos presos proveem da investigação dos conhecidos "crimes de rua" (furto, roubo, tráfico de drogas, etc.), os quais são objetos das ordens de busca e apreensão em favelas e comunidades subalternizadas. Crimes contra a ordem tributária e lavagem de dinheiro nem sequer aparecem nos dados, em razão da ínfima quantidade; crimes contra a Administração Pública representam 0,41\% do total de detentos.

Esses números demonstram que os direitos humanos estão vinculados aos interesses políticos e às estruturas econômicas e sociais, de maneira que as medidas de tutela penal, como as ordens de busca e apreensão, são na verdade violentos instrumentos de dominação, manutenção do pensamento hegemônico e exclusão dos mais débeis ao poder punitivo.

\footnotetext{
${ }^{25}$ Superior Tribunal de Justiça. Recurso em Habeas Corpus $n^{\circ}$ 16.792/GO. Quinta Turma. Ministro relator Gilson Dipp. Data de julgamento 02 de junho de 2005.

${ }^{26}$ Superior Tribunal de Justiça. Habeas Corpus n 55.986/RJ. Quinta Turma. Ministro relator Gilson Dipp. Data de julgamento 06 de junho de 2006.

${ }^{27}$ BRASIL. Ministério da Justiça Governo Federal. Estatística InfoPen. Disponível em: <http://www.justica.gov.br/seus-direitos/politica-penal/transparencia-institucional/estatisticasprisional/anexos-sistema-prisional/total-brasil-junho-2013.pdf> Acesso em: 20 dez. 2014.
} 
Alexandre Bizzotto, ao analisar a perniciosidade do discurso garantista, identifica que em determinados momentos a construção normativa é extremamente flexível e em outros é excessivamente rígida para a efetivação dos direitos humanos ${ }^{28}$.

Numa perspectiva formal-positivista, a restrita obediência às normas jurídicas, retira do magistrado a capacidade de interpretar ao texto legal e elimina qualquer possibilidade de avaliação da justiça ou da legitimidade do direito positivado. Essa rígida vinculação à legalidade, atrelada ao falacioso fundamento da segurança jurídica, cega o intérprete na convalidação dos direitos humanos.

Por outro lado, na ânsia de tutelar penalmente os interesses sociais redimensionados na perspectiva promocional do Estado, acentua-se a utilização dos direitos humanos para amparar e legitimar a ampliação do poder punitivo. Flexibilizam-se as construções normativas, numa tentativa discursiva de deixar maleável a aplicação das garantias constitucionais de natureza penal para abstratamente proteger bens jurídicos.

No âmbito das medidas acautelatórias penais, como as ordens de busca e apreensão coletivas, não se pode inferir que a rigidez normativa impeça a aplicação dos direitos fundamentais. Não há restrição normativa ou imobilidade interpretativa, pelo contrário, existe uma "falsificação" na construção linguística das decisões judiciais, com artifícios nas fundamentações e amplo subjetivismo na exegese da norma, que facilmente desvia das finalidades precípuas dos direitos humanos. Na realidade, a inversão ideológica aloja-se nas abstrações jurídicas que sucumbem a proteção jurídica penal a uma função simbólica de efetivação da “justiça social” (clamor público).

Os princípios da defesa social tratam de atribuir à pena funções utilitárias, como a prevenção geral negativa (intimidação) e a prevenção especial positiva (ressocialização), e representam uma sedutora ideia de legitimar o exercício do poder do sistema penal. David Garland pontua que as medidas penais operam em duas dimensões distintas: uma escala punitiva, que utiliza os símbolos de condenação e sofrimento para transmitir sua mensagem, e uma dimensão instrumental, preocupada com a proteção do público e com a administração de riscos. Ambas as dimensões possuem uma estratégia segregacionista e estigmatizadora, de maneira que a nova preocupação do sistema penal não é puramente punitiva e nem somente

${ }^{28}$ BIZZOTTO, Alexandre. A inversão ideológica do discurso garantista: a subversão da finalidade das normas constitucionais de conteúdo limitativo para ampliação do sistema penal, p. 132-145. 


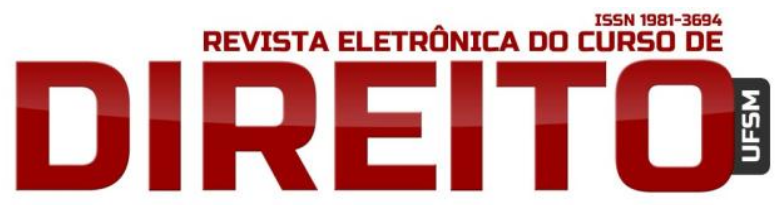

A “TERCEIRA MARGEM" DOS DIREITOS HUMANOS: PARA ALÉM DO PODER PUNITIVO VIA MANDADO DE BUSCA E APREENSÃO COLETIVO

orientada à tutela da sociedade. 0 novo ideal penal é que o público seja protegido e que seus "sentimentos sejam expressados"29.

Contudo, a missão da tutela penal é a defesa do humano e de suas liberdades, o que não se coaduna com a função retórica de proteção de bens jurídicos fundamentais, construída pela mera manipulação da linguagem ${ }^{30}$.

É necessário promover uma visão emancipatória dos direitos humanos, livre do cativeiro encantatório normativo e das eloquências populistas. Nesse sentido, a literatura se mostra um caminho hábil para a análise crítica dos direitos humanos.

\section{A TERCEIRA MARGEM DO RIO: UM DIÁLOGO CRÍTICO COM OS DIREITOS HUMANOS}

A literatura e o direito possuem uma íntima relação, pois ambos são expressão da sociedade. 0 fenômeno literário é um instrumento de crítica, justamente porque a arte é uma criação em um meio, por um artista situado num contexto temporal e ambiental. A literatura promove a contemplação crítica do pensamento jurídico, ao fornecer elementos que provoquem o questionamento acerca das tendências sociais, políticas de uma época e atuem sobre o status social no sentido de denúncia, protesto e transformação ${ }^{31}$.

João Guimarães Rosa é uma das principais referências da terceira fase do Modernismo, também conhecido como "Modernismo na Ficção". Fase literária delineada entre os anos de 1945 e meados de 1960, historicamente marcada pelo final da $2^{\text {a }}$ Guerra Mundial: período de reconstrução da sociedade e de reação ao conservadorismo eurocêntrico imposto através do Romantismo e Naturalismo. Os textos rosianos apresentam uma linguagem genuinamente brasileira, com a reprodução da natureza e da realidade social de um povo. Os contos são de caráter regionalista, com empregos de expressões coloquiais e neologismos, cuja principal característica é a numerosa carga semântica que está inserida nas palavras.

\footnotetext{
${ }^{29}$ GARLAND, David. A cultura do controle: crime e ordem social na sociedade contemporânea, p. 315-316. ${ }^{30}$ ANDRADE, Vera Regina Pereira de. A ilusão de segurança jurídica: do controle da violência à violência do controle penal, p. 180.

31 COUTINHO, Afrânio. Caminhos do pensamento crítico. 1. ed. Vol. 2. Rio de Janeiro: Americana Prolivro, 1974, p. 03.
} 
A "TERCEIRA MARGEM" DOS DIREITOS HUMANOS: PARA ALÉM DO PODER PUNITIVO VIA MANDADO DE BUSCA E APREENSÃO COLETIVO

LaRISSA Rosa, MARISA Helena D’ARBo AlVES de FreITAS, RENAN POSELLA MANDARINO

Para apresentar a essência de seus personagens, justamente pela necessidade de “narrar o inarrável, capturar o incapturável” ${ }^{32}$, Rosa provocou uma revolução estilística, com a subversão instrumental, ao dilacerar a linguagem unidimensional, rasa, maculada pelos clichês ou fórmulas feitas. Fechou o universo da alocução ao recusar a antilinguagem. Ademais, os personagens guimarosianos são psicologicamente complexos, com o sujeito humano em constante conflito com o meio em que está inserido. Há uma dimensão metafísica e ontológica da alma humana referida à solidão existencial.

A genialidade de Guimarães Rosa centra no fato de que um singelo conto possibilita amplas análises e pluralidade de dimensões interpretativas. "A terceira margem do rio" narra a estória de um velho homem que, solitariamente, decide descobrir como chegar à terceira margem do rio, remando "rio abaixo, rio a fora, rio a dentro"33. Por ter esse comportamento, ele é tratado como um louco, desequilibrado, diferente em relação às demais pessoas da comunidade. Seu filho é o narrador-personagem e, em seus relatos, transmite um ser humano cujos ideais de vida divergem dos padrões aceitos como normais, apresentando o personagem principal atitudes que perturbam seus familiares e conhecidos. Ele é o único que persiste na compreensão da opção do pai, que não se descuida dele e chega a desejar substituí-lo na busca pela terceira margem do rio. Mas não consegue, pois sofre o "grave dos medos", falta-lhe a coragem para o salto. Carrega a vida como um fardo e envelhece com as "bagagens da vida". A escolha do isolamento no rio instiga permanentemente o filho, o qual é levado a questionar o próprio existir humano, perceptíveis nas indagações durante a narrativa. Verifica-se uma perene preocupação com o destino humano.

Há pelo menos três modos diferentes de analisar a decisão de o personagem permanecer no meio do rio, dentro da canoa: a loucura; o encontro com a morte e a esperança de encontrar um mundo inexplorado, idealizado pelo narrador. Interessante notar que nas culturas orientais, o rio simboliza a vida, a existência humana, de maneira que a decisão do velho conota sua necessidade de conhecer as profundezas de seu próprio espírito ${ }^{34}$.

Estabelecendo um diálogo provocativo com os direitos humanos, o rio pode ser compreendido como o campo normativo, responsável por pautar abstratamente os direitos: "Rio

\footnotetext{
${ }^{32}$ COUTINHO, Afrânio. A literatura no Brasil: era modernista. 4. ed. Vol. 5. São Paulo: Global, 1997, p. 519.

${ }^{33}$ ROSA, João Guimarães. A terceira margem do rio. In: Primeiras estórias. 40. ed. Rio de Janeiro: Nova Fronteira, 1988, p. 37.

${ }^{34}$ BUHLER, Andréa de Morais Costa. As margens do devaneio: uma análise do conto "A terceira margem do rio" de João Guimarães Rosa. Revista Graphos, João Pessoa, v. 8, n 1, p.59-62, jan./jul. 2006, p. 60.
} 
A "TERCEIRA MARGEM" DOS DIREITOS HUMANOS: PARA ALÉM DO PODER PUNITIVO VIA MANDADO DE BUSCA E APREENSÃO COLETIVO

por aí se estendendo grande, fundo, calado que sempre. Largo, de não se pode ver a forma da outra beira”35. Assim como rio, existe uma extensa quantidade de leis. Contudo, a norma jurídica é estática, "calada que sempre" ${ }^{36}$, pois sua aplicação depende do significado que se depreende dela. Enclausurada nesse subjetivismo ideológico, a legalidade é instrumento de dominação dos humanos mais vulneráveis. Essa unidimensionalidade interpretativa impede a análise dos direitos humanos pelo viés emancipatório, com o escopo de "ver a forma da outra beira"37.

A canoa representa os instrumentos aptos para construção dos direitos em integração social, com maior participação dos marginalizados. As respostas contra as opressões e dominações não estão nos centros, nas normas, leis e tratados, estão nas margens, nas práxis, nos revoltados, nos indignados, nos historicamente subalternizados, que sentem na pele e na alma todo o peso do mundo ${ }^{38}$. Assim, a canoa deve ser simples, porém “forte e arqueada em rijo, própria para dever durar na água por uns vinte ou trinta anos” ${ }^{39}$, com o escopo de resistir ao rio da normatividade.

Os personagens revelam um embate de valores humanos. De um lado, a loucura de um velho em desbravar o rio em busca de um ideal maior. De outro, o narrador, em ato de solidariedade, se oferece para ficar no lugar de seu pai na canoa; contudo, falta-lhe a coragem para assumir tamanha virtude: "E eu não podia... Por pavor, arrepiados os cabelos, corri, fugi, me tirei de lá, num procedimento desatinado" ${ }^{40}$. No plano existencial, os direitos humanos são criados para si e para o outro, ou seja, há uma solidariedade ontológica entre o existir para si e o existir digno do outro, de maneira que a concretização desses direitos fundamentais visa a possibilitar aos homens a "existência autêntica em coexistência" ${ }^{41}$. Entretanto, o medo abala a solidariedade. 0 receio de aceitar o outro como sujeito de direitos é um dos maiores entraves para edificação efetiva de uma sociedade justa e igualitária.

\footnotetext{
${ }^{35}$ ROSA, João Guimarães. A terceira margem do rio, p. 32.

${ }^{36}$ ROSA, João Guimarães. A terceira margem do rio, p. 33.

37 ROSA, João Guimarães. A terceira margem do rio, p. 32.

${ }^{38}$ FALEIROS JÚNIOR, Roberto Galvão. Tutela penal e teoria crítica de direitos humanos: uma intersecção crítico-dialética marginal, p. 158.

${ }^{39}$ ROSA, João Guimarães. A terceira margem do rio, p. 32.

${ }^{40}$ ROSA, João Guimarães. A terceira margem do rio, p. 37.

${ }^{41}$ GRANDUQUE JOSÉ, Caio Jesus. A construção existencial dos direitos humanos. 2009. 194 f. Dissertação (Mestrado em Direito) - Universidade Estadual Paulista. Faculdade de Ciências Humanas e Sociais, Franca, 2009, p. 131.
} 
Apesar das dificuldades, a loucura é necessária para remar contra o rio taciturno da legalidade imposta pelas ideologias da classe dominante. É preciso direcionar os direitos humanos para uma "terceira margem", para além do poder punitivo que oprime os setores subalternos da sociedade, conforme se vislumbra nas ordens de busca e apreensão coletiva.

\section{A “TERCEIRA MARGEM” DOS DIREITOS HUMANOS: PARA ALÉM DO PODER PUNITIVO VIA MANDADO DE BUSCA E APREENSÃO COLETIVO}

O senso comum teórico que baseia a motivação das decisões judiciais sobre busca e apreensão coletiva é o de que são "operações de saturação para prevenir crimes"42 ou, ainda, medidas para "garantir a lei e ordem da sociedade" ${ }^{43}$, principalmente quando se trata de crimes de porte de armas e tráfico de drogas. Esse discurso simplista de busca pela justiça social, que retroalimenta o sistema penal, esconde um discurso complexo de imposição da classe dominante e aniquilamento dos direitos humanos.

Utiliza-se a atividade policial, respaldada no controle punitivo do judiciário, com a finalidade de objetificação e homogeneização dos indivíduos de classe inferiorizada. A promessa de certeza e segurança jurídica e de racionalização das medidas penais ocultam a relação de poder e dominação que existe na justiça penal ${ }^{44}$.

Michel Foucault aponta para existência da "sociedade da normalização”, cuja “norma”, no sentido de padronização, é o seu elemento fundamental de caracterização. É uma sociedade que sofre tanto com a norma da disciplina (poder disciplinar), centrada no corpo individual, quanto à norma da regulamentação (poder biopolítico), centrada na vida humana, ambas com o latente viés neutralizante. 0 Estado assume, então, estratégias de “normalização” da população, ou seja, através do poder disciplinar busca "adestrar o indivíduo e extorquir suas

\footnotetext{
${ }^{42}$ G1 GLOBO. SSPDS cumpre mandado de busca e apreensão coletivo em comunidade. Disponível em: <http://g1.globo.com/ceara/noticia/2014/08/sspds-cumpre-mandado-de-busca-e-apreensao-coletivo-emcomunidade.html $>$. Acesso em: 19 jan. 2015.

${ }^{43}$ CONSULTOR JURÍDICO. Mandado coletivo revista casas e favelas no Rio de Janeiro. Disponível em: <http://www.conjur.com.br/2014-mar-31/justica-mandado-coletivo-revista-casas-favela-rio-janeiro>. Acesso em: 05 mar. 2015.

44 FOUCAULT, Michel. Vigiar e punir: história da violência nas prisões. Tradução de Ligia M. Pondé Vassalo. Petrópolis: Vozes, 1987, p. 80-90.
} 
A "TERCEIRA MARGEM" DOS DIREITOS HUMANOS: PARA ALÉM DO PODER PUNITIVO VIA MANDADO DE BUSCA E APREENSÃO COLETIVO

Larissa Rosa, marisa Helena d’ARbo Alves de Freitas, RENAN POSELLA MANDARINO

forças" ${ }^{45}$. As investigações ilegalmente realizadas nas favelas e comunidades subalternizadas não passam de uma técnica específica de poder que toma os indivíduos como objetos e ao mesmo tempo como instrumentos de exercício do poder estatal.

Diante das características autoritária e seletiva que marcam o poder punitivo, o qual reproduz concepções, propostas e ideologias conservadoras, as violações aos direitos humanos se tornam comum. Nem mesmo no plano normativo, que apenas serve de parâmetro mínimo para efetivação dos direitos, há o devido respeito às garantias processuais, como bem se comprova a partir da leitura das decisões judiciais referidas no trabalho.

É perceptível na cultura judiciária brasileira a incorporação de determinadas formas de produção da verdade que permite a manutenção e transcendência da lógica inquisitória. A formação decisionista-inquisitorial dos operadores jurídicos, sobretudo dos juízes, revela a profunda incapacidade de apreensão das angústias das partes envolvidas. Salo de Carvalho sustenta que a formação inquisitória dos atores da persecução penal representa um dos principais obstáculos à reforma e à democratização do sistema punitivo nacional. A figura do acusador e do julgador são os principais filtros ao punitivismo, porém, a mentalidade excessivamente técnica e inquisitorialista impede a efetivação democrática dos direitos humanos no processo penal ${ }^{46}$.

Em pesquisa realizada pela Procuradoria Geral de Justiça em convênio com a Universidade Federal do Rio Grande do Sul, ao indagar os Promotores de Justiça sobre sua opção político-criminal, $54,4 \%$ dos pesquisados identificaram-se com as políticas de tolerância zero, $26,9 \%$ aderiram ao funcionalismo penal e $8,2 \%$ demonstraram-se influenciados pelo garantismo penal $^{47}$.

O discurso humanitário e garantidor, de que "casa é asilo inviolável", está majoritariamente a serviço do poder burguês. Há uma explícita dominação dos setores marginalizados da sociedade, através do ius puniendi, que afronta os preceitos basilares de direitos humanos, os quais são, em sua essência, horizontes de esperança, o caminho por onde

\footnotetext{
${ }^{45}$ FOUCAULT, Michel. Em defesa da sociedade. Tradução de Maria Hermantina Galvão. São Paulo: Martins Fontes, 1999, p. 33 e 302.

${ }^{46}$ CARVALHO, Salo de. 0 papel dos atores do sistema penal na era do punitivismo: o exemplo privilegiado da aplicação da pena. Rio de Janeiro: Lumen Juris, 2010, p. 97.

47 CARVALHO, Salo de. O papel dos atores do sistema penal na era do punitivismo: o exemplo privilegiado da aplicação da pena, p. 101.
} 


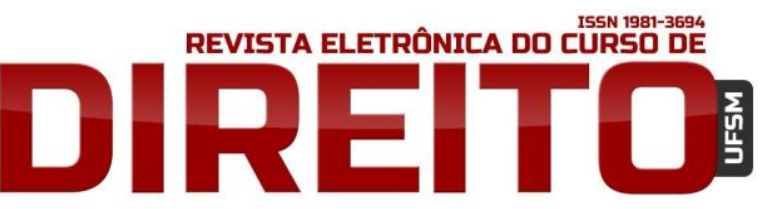

A “TERCEIRA MARGEM" DOS DIREITOS HUMANOS: PARA ALÉM DO PODER PUNITIVO VIA MANDADO DE BUSCA E APREENSÃO COLETIVO

Larissa Rosa, marisa Helena d’ARbo Alves de Freitas, RENAN POSELLA MANDARINO

deve se trilhar as práticas sociais e institucionais para que ocorra o empoderamento dos sujeitos ${ }^{48}$.

A “terceira margem" dos direitos humanos reside nesse horizonte de esperança, com a permanente construção dos direitos que sejam expressão da liberdade material do homem, da emancipação de sua consciência e da promoção humana solidária. Direitos esses que são construídos e reconstruídos cotidianamente, numa transformação constante e de longo alcance. O direito não é, mas está sempre sendo.

\section{CONCLUSÃO}

O conteúdo abstrato dos direitos humanos e a excessiva confiança no plano normativo permitem que ocorra uma hegemonia de grupos sobre outros grupos, como bem se conclui no exame das práticas punitivistas. A construção cotidiana de direitos e a participação solidária dos indivíduos são os caminhos para além da violência punitiva institucionalizada.

O sistema carece de resistência contra os poderes opressores instituídos, ou seja, faltam indivíduos que concretamente rejeitem o discurso encantatório delineado pela sociedade punitivista. Essa carência de oposição é perceptível tanto no plano horizontal, com a escassez de movimentos sociais irresignados com os abusos da violência do controle penal, quanto no vertical, com parca quantidade de representantes do Executivo, Legislativo e Judiciário que refutem o amplo poder punitivo.

Parcos são os juristas irresignados contra essa perniciosa prática seletiva e opressora pulsante no sistema penal brasileiro. Em conformidade com o conto de Guimarães Rosa, há canoas, mas existem poucos velhos desbravados dispostos a remar contra a corrente do rio em busca da terceira margem. Para alterações contundentes nos sistemas penais, necessária uma profunda mudança no comportamento humano, uma alteração na racionalidade dos detentores do saber jurídico e da própria sensibilidade cultural do corpo social em direção à promoção da cooperatividade entre os indivíduos.

${ }^{48}$ GALLARDO MARTíNEZ, Helio. Teoría crítica: matriz y posibilidad de derechos humanos, p. 237. 


\section{REFERÊNCIAS}

ANDRADE, Vera Regina Pereira de. A ilusão de segurança jurídica: do controle da violência à violência do controle penal. Porto Alegre: Livraria do Advogado, 2003.

BIZZOTTO, Alexandre. A inversão ideológica do discurso garantista: a subversão da finalidade das normas constitucionais de conteúdo limitativo para ampliação do sistema penal. Rio de Janeiro: Editora Lumen Juris, 2009.

BRASIL. Ministério da Justiça Governo Federal. Estatística InfoPen. Disponível em: <http://www.justica.gov.br/seus-direitos/politica-penal/transparenciainstitucional/estatisticas-prisional/anexos-sistema-prisional/total-brasil-junho-2013.pdf > Acesso em: 20 dez. 2014.

BUHLER, Andréa de Morais Costa. As margens do devaneio: uma análise do conto "A terceira margem do rio” de João Guimarães Rosa. Revista Graphos, João Pessoa, v. 8, n 1, p.59-62, jan./jul. 2006.

CONSULTOR JURÍDICO. Mandado coletivo revista casas e favelas no Rio de Janeiro. Disponível em: <http: / /www.conjur.com.br/2014-mar-31/justica-mandado-coletivo-revista-casas-favelario-janeiro>. Acesso em: 05 mar. 2015.

CARVALHO, Salo de. 0 papel dos atores do sistema penal na era do punitivismo: o exemplo privilegiado da aplicação da pena. Rio de Janeiro: Lumen Juris, 2010.

Antimanual de criminologia. 4. ed. Rio de Janeiro: Lumen Juris, 2011.

CORRÊA, Douglas. Mandado de busca coletivo autoriza revista a casas do Complexo da Maré. UOL notícias cotidiano, Rio de janeiro, 30 mar. 2014. Disponível em:

<http://noticias.uol.com.br/cotidiano/ultimas-noticias/2014/03/30/mandado-de-buscacoletivo-autoriza-revista-a-casas-do-complexo-da-mare.htm>. Acesso em: 03 abr. 2015.

COUTINHO, Afrânio. Caminhos do pensamento crítico. 1. ed. Vol. 2. Rio de Janeiro: Americana Prolivro, 1974.

A literatura no Brasil: era modernista. 4. ed. Vol. 5. São Paulo: Global, 1997.

FALEIROS JÚNIOR, Roberto Galvão. Tutela penal e teoria crítica de direitos humanos: uma intersecção crítico-dialética marginal. 2012. 204 f. Dissertação (Mestrado em Direito) Universidade Estadual Paulista. Faculdade de Ciências Humanas e Sociais, Franca, 2012.

FOUCAULT, Michel. Vigiar e punir: história da violência nas prisões. Tradução de Ligia M. Pondé Vassalo. Petrópolis: Vozes, 1987. 
Fontes, 1999.

Em defesa da sociedade. Tradução de Maria Hermantina Galvão. São Paulo: Martins

G1 GLOBO. SSPDS cumpre mandado de busca e apreensão coletivo em comunidade. Disponível em: <http://g1.globo.com/ceara/noticia/2014/08/sspds-cumpre-mandado-de-busca-eapreensao-coletivo-em-comunidade.html>. Acesso em: 19 jan. 2015.

GALLARDO MARTÍNEZ, Helio. Teoría crítica: matriz y posibilidad de derechos humanos. Murcia: Editado por David Sánchez Rubio, 2008.

GARLAND, David. A cultura do controle: crime e ordem social na sociedade contemporânea. Pensamento criminológico, vol. 16. Rio de Janeiro: Revan, 2008.

GIDDENS, Anthony. Modernidade e identidade. Tradução de Plínio Dentzien. Rio de Janeiro: Jorge Zahar, 2002.

GRANDUQUE JOSÉ, Caio Jesus. A construção existencial dos direitos humanos. 2009. $194 \mathrm{f}$. Dissertação (Mestrado em Direito) - Universidade Estadual Paulista. Faculdade de Ciências Humanas e Sociais, Franca, 2009.

HERRERA FLORES, Joaquín. Los derechos humanos como produtos culturales: crítica del humanismo abstracto. Madrid: Los Libros De La Catarata, 2005.

. La Reinvención de los Derechos Humanos. Colección Ensayando. Sevilla:

Atrapasueños, 2007.

LOPES JUNIOR, Aury. Introdução crítica ao Processo Penal: Fundamentos da Instrumentalidade Constitucional. 4. ed. Rio de Janeiro: Lumen Juris, 2006.

Direito Processual Penal. 11. ed. São Paulo: Saraiva, 2014.

PITOMBO, Cleunice Valentim Bastos. Licitude da prova obtida por meio da busca e da apreensão. In: VILARD, Celso Sanchez; PEREIRA, Flávia Rahal Bresser; NETO, Theodomiro Dias Neto. Direito penal econômico: crimes econômicos e processo penal. São Paulo: Saraiva, 2008.

ROSA, João Guimarães. A terceira margem do rio. In: Primeiras estórias. 40. ed. Rio de Janeiro: Nova Fronteira, 1988.

SÁNCHEZ RÚBIO, David. Reversibilidade do direito: os direitos humanos na tensão entre o mercado, os seres humanos e a natureza. Revista de Estudos Criminais, ano VI, $\mathrm{n}^{\circ} 22$. Porto Alegre: Notadez/PPGCRIm PUCRS/ITEC, 2006.

. Encantos e desencantos dos direitos humanos: emancipações, libertações e dominações. Porto Alegre: Livraria do Advogado, 2014.

SARLET, Ingo Wolfgang; NETO, Jayme Weingartner. A inviolabilidade do domicílio e seus limites: o caso do flagrante delito. Revista de Direitos Fundamentais e Democracia, Curitiba, v. 14, $\mathrm{n}^{\circ}$ 14, p. 544-562, jul./dez. 2013. 
ISSN 1981-3694

(DOI): 10.5902/1981369418759

REVISTA ELETRÔNICA DO CURSD DE

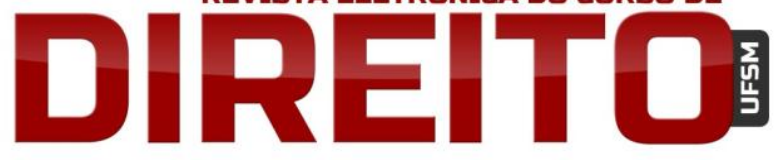

A "TERCEIRA MARGEM" DOS DIREITOS HUMANOS: PARA ALÉM DO PODER PUNITIVO VIA MANDADO DE BUSCA E APREENSÃO COLETIVO

ZAFFARONI, Eugenio Raúl. Em busca de las penas perdidas: Deslegitimacion y dogmática juridico-penal. 2. ed. Buenos Aires: EDIAR, 1998.

; BATISTA, Nilo; ALAGAIA, Alejandro; SLOKAR, Alejandro. Direito penal brasileiro:

primeiro volume - parte geral. Rio de Janeiro: Revan, 2003.

Recebido em: 10.07.2015 / Aprovado em: 16.09.2015 